\title{
Thoracic Limb Morphology of the Ring-tailed Lemur (Lemur catta) Evidenced by Gross Osteology and Radiography
}

\author{
M. Makungu ${ }^{1 *}$, H. B. Groenewald ${ }^{1}$, W. M. du Plessis ${ }^{2}$, M. Barrows ${ }^{3}$ and K. \\ N. Koeppel ${ }^{4}$ \\ ${ }^{1}$ Department of Anatomy and Physiology, Faculty of Veterinary Science, University of Pretoria, Private \\ Bag X04, Onderstepoort 0110, South Africa; \\ ${ }^{2}$ Ross University School of Veterinary Medicine, P. O Box 334, Basseterre, St. Kitts, West Indies; \\ ${ }^{3}$ Bristol Zoo Gardens, Clifton, Bristol BS8 3HA, UK; \\ ${ }^{4}$ Johannesburg Zoo, Private Bag X13, Parkview, Johannesburg 2122, South Africa
}

\section{${ }^{*}$ Correspondence}

Tel.: +27 125298246 ;

Fax: +27 125298320

e-mail: modesta_makungu@yahoo.com

\section{Summary}

There is limited information available on the morphology of the thoracic limb of the ringtailed lemur (Lemur catta). This study describes the morphology of the thoracic limb of captive ring-tailed lemurs evidenced by gross osteology and radiography as a guide for clinical use. Radiographic findings of 12 captive ring-tailed lemurs are correlated with bone specimens of three adult animals. The clavicle is well developed. The scapula has a large area for the origin of the $\mathrm{m}$. teres major. The coracoid and hamate processes are 
well developed. The lateral supracondylar crest and medial epicondyle are prominent. The metacarpal bones are widely spread, and the radial tuberosity is prominent. These features indicate the presence of strong flexor muscles and flexibility of thoracic limb joints, which are important in arboreal quadrupedal locomotion. Furthermore, an ovoid ossicle is always seen at the interphalangeal joint of the first digit. Areas of increased soft tissue opacity are superimposed over the proximal half of the humerus and distal half of the antebrachium in male animals as a result of the scent gland. Knowledge of the morphology of the thoracic limb of individual species is important for accurate interpretation and diagnosis of musculoskeletal diseases.

\section{Introduction}

The ring-tailed lemur (Lemur catta) is classified as an endangered species by the International Union for Conservation of Nature and Natural Resources (IUCN, 2014). It is primarily distributed in south and south-western Madagascar (Budnitz and Dainis, 1975). The ring-tailed lemur belongs to the suborder strepsirrhini (Nowak, 1999). Most strepsirrhines resemble more primitive animals by retaining characteristics such as prominent scent glands, the rhinarium and a pointed muzzle (Jungle, 2003; AnkelSimons, 2007).

Radiography is a non-invasive diagnostic imaging modality (Owens and Biery, 1999a), which is indicated for the diagnosis, evaluation and monitoring the progression of healing of various conditions affecting the musculoskeletal system (Burk and Feeney, 2003). It is commonly used as the first diagnostic imaging modality for the musculoskeletal system in exotic animal practice. Diseases of lemurs involving the 
musculoskeletal system, where radiography was used as the first diagnostic imaging modality, include idiopathic proliferative bone disease characterized by irregular enlargement of bones of the distal limbs as a result of periosteal proliferation (Weber et al., 1995), nutritional secondary hyperparathyroidism (Tomson and Lotshaw, 1978), multifocal pyogranulomatous osteomyelitis (Backues et al., 2001), periarticular hyperostosis (Jungle et al., 1994) and neoplasia such as osteosarcoma (Warwick, 1951). However, limited information is available about the normal gross osteology and radiographic anatomy of the appendicular skeleton of lemurs (Jouffroy, 1975; Roberts and Davidson, 1975).

Knowledge of the normal gross osteology and radiographic anatomy is important for accurate interpretation and diagnosis of various conditions, which involve the musculoskeletal system (Owens and Biery, 1999b; Smallwood and Spaulding, 2013; Thrall, 2013). Normal gross osteology and radiographic anatomy of the thoracic limb in companion animals is well documented and serves as a guide for diagnosis of various musculoskeletal diseases. (Nickel et al., 1986; Thrall and Robertson, 2011; Smallwood and Spaulding, 2013). This study describes the morphology of the thoracic limb of captive ring-tailed lemurs evidenced by gross osteology and radiography.

\section{Materials and methods}

\section{Sample population}

Twelve (11 live and one dead) adult, intact, skeletally mature captive ring-tailed lemurs without any previous history of lameness were used for the radiographic study. Live animals were clinically healthy, and radiography was performed during their annual 
health examination under general anaesthesia. Of the 11 live animals, eight were females and three were males whose age ranged from 2.8 to 25.7 years (mean: $10.8 \pm$ 7.6 years). Their minimum and maximum weights were $2.4 \mathrm{~kg}$ and $3.4 \mathrm{~kg}$, respectively, (mean: $3.0 \pm 0.3 \mathrm{~kg}$ ). Of the 11 live animals, one female $(7.3$ year old; $2.8 \mathrm{~kg}$ ) died during the course of the study and was included in the gross osteological study. One dead female animal ( 5 year old; $2.8 \mathrm{~kg}$ ), which had died from a cause unrelated to disease of the musculoskeletal system was included in the study.

Bone specimens of the thoracic limb of three adult skeletally mature animals, one from the Transvaal museum (male of unknown age) and the two dead females mentioned above, were used for gross osteological study. The study was approved by the Animal Use and Care Committee (AUCC) of the University of Pretoria.

\section{Radiography}

Radiography of the right thoracic limb was performed using a tabletop technique. In six animals, a Roentgen 703 X-ray machine (GEC Medical Equipment Ltd, Middlesex, England) was used at a source to image distance (SID) of $105 \mathrm{~cm}$ with $60 \mathrm{kVp}$ and 3 mAs. Images were obtained using a computed radiography (CR) unit (Regius Model 110, Konica Minolta Medical and Graphic, INC., Tokyo, Japan). In five animals, a EVAHF525 X-ray machine (Comed Medical System Co. Ltd, Kyunggi, Korea) was used at a SID of $95 \mathrm{~cm}$ with $46 \mathrm{kVp}$ and $5 \mathrm{mAs}$. Mammography films (UM-MA, Fujifilm Corporation, Tokyo, Japan) were used in combination with mamoray screens (Fujifilm

Europe $\mathrm{GmbH}$, Duesseldorf, Germany), and an automatic X-ray film processor model CP-345 (ELK Corporation, Tokyo, Japan) was used. In the remaining animal, radiography was performed using a Siemens Polymat 50 (Siemens, Munich, Germany) 
X-ray machine at a SID of $100 \mathrm{~cm}, \mathrm{kVp}$ range of $48-58$ and $\mathrm{mAs}$ range of $4-5$. Images were obtained using a CR unit (Fuji Axim FCR Capsula XL, Fujifilm Corporation, Tokyo, Japan).

A mediolateral $(\mathrm{ML})$ view of the right thoracic limb was taken with the animal in right lateral recumbency. The radiograph included the right front leg from the shoulder joint to the distal aspect of the digits. To obtain a true ML view of the thoracic limb, tape was applied around the carpus and secured on the cassette to maintain the antebrachium and manus in a pronated position to prevent supination. To avoid the superimposition of the clavicle over the scapula on the ML view, the cranial margin of the right scapula was positioned at the level of the cranial margin of the manubrium sterni or slightly caudally.

Additionally, a caudocranial $(\mathrm{CdCr})$ view of the right shoulder, a craniocaudal (CrCd) view of the right elbow and a dorsopalmar (DPa) view of the right manus were taken. A CdCr view of the shoulder joint was taken with the animal in dorsal recumbency and collimation included the distal half of the scapula and the proximal half of the humerus. The $\mathrm{CrCd}$ view of the elbow joint and DPa view of the manus were obtained with the animal in sternal recumbency. Collimation of the elbow joint included the distal humerus and proximal radius and ulna. For the manus, collimation included the distal radius and ulna and distal aspect of the digits.

\section{Gross osteology}

The gross osteology of the thoracic limb was described. Radiographic findings were correlated with the gross osteologic findings. Digital photographs of the clavicle, humerus, radius, ulna and carpus were taken with CANON 5DMARK2 (Canon Inc., 
Tokyo, Japan) for illustration. The clavicle, scapula, humerus, radius and ulna were photographed in cranial and lateral views, and the carpus was photographed in a dorsal view. In addition, caudal (clavicle, scapula and humerus), medial (clavicle and humerus) and distal (scapula) photographic views were also taken.

\section{Bone measurements}

Bone measurements of the right thoracic limb were performed on the radiographic images with the exception of the scapula, which was performed on bone specimens. The maximum lengths of bones were measured from the proximal to the distal extremities. The maximum lengths of the humerus, radius and ulna were measured on the $\mathrm{ML}$ radiographic view. For the metacarpal bones and phalanges, the maximum lengths were measured on the DPa radiographic view of the manus. The craniocaudal diameter of the scapula was measured as the maximum distance perpendicular to the maximum length. Radiographic measurements were not compensated for magnification.

\section{Statistical analysis}

Statistical analysis was performed using Stat View ${ }^{\odot}$ (SAS Institute Inc., NC, USA) statistical package. A descriptive statistical analysis was performed for the age and weight of the animal, and the length and craniocaudal diameter of the bones. Data were expressed as mean \pm standard deviation (SD) and the range. 


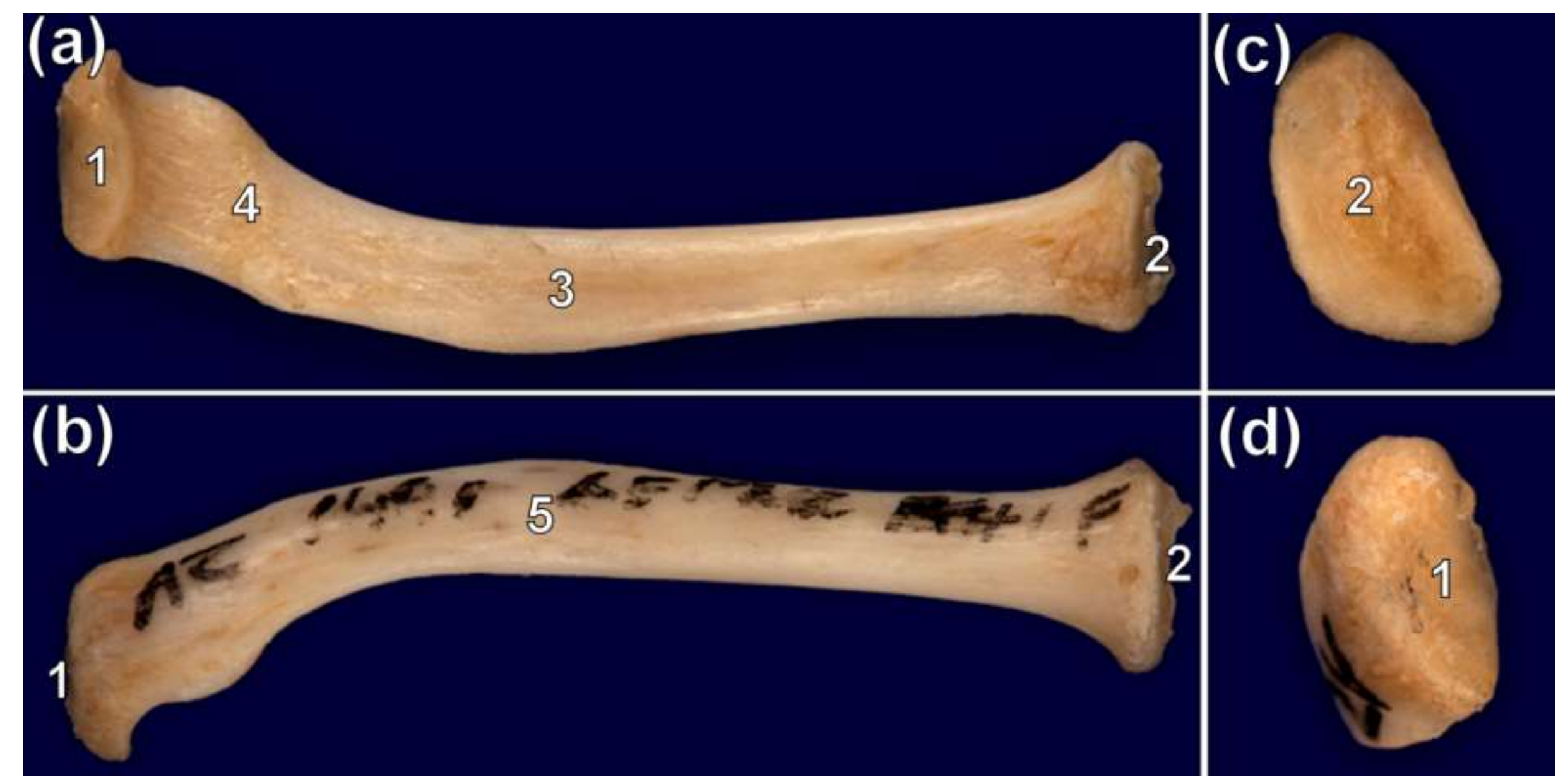

Fig. 1. Caudal (a), cranial (b), medial (c) and lateral (d) views of a bone specimen of the clavicle of an adult male ring-tailed lemur. (1) acromial facet, (2) sternal facet, (3) caudal surface, (4) trapezoid line and (5) cranial surface. 


\section{Results}

\section{Clavicle}

The clavicle is well developed (Figs 1 and 2). The sternal extremity has an almost semicircular articular facet for articulation with the Manubrium sterni (Fig. 1c). The acromial extremity bears a fusiform facet for articulation with the hamate process of the scapula (Fig. 1d). On the ML radiographic view of the shoulder joint, the clavicle projects cranially to the craniodistal aspect of the scapula, whereas on the $\mathrm{CdCr}$ radiographic view of the shoulder joint, it is seen distal to the scapula with its acromial extremity superimposed on the medial half of the proximal aspect of the humerus (Fig. 2). A distinct articulation between the hamate process of the scapula and acromial extremity of the clavicle is seen on both the $\mathrm{ML}$ and $\mathrm{CdCr}$ radiographic views of the shoulder joint (Fig. 2). Measurements of bones of the thoracic limb are shown in Tables 1 and 2.

Table 1. Measurements $(\mathrm{cm})$ of the scapula, humerus, radius and ulna of the right thoracic limb in captive ring-tailed lemurs

\begin{tabular}{|c|c|c|c|c|}
\hline Bone & Variables & $\begin{array}{l}\text { Number of } \\
\text { animals }\end{array}$ & Mean \pm SD $(\mathrm{cm})$ & Range $(\mathrm{cm})$ \\
\hline \multirow[t]{2}{*}{ Scapula } & Length $^{a}$ & 3 & $5.40 \pm 0.10$ & $5.30-5.50$ \\
\hline & Craniocaudal diameter $^{a}$ & 3 & $2.60 \pm 0.30$ & $2.30-2.90$ \\
\hline Humerus & Length $^{\mathrm{b}}$ & 12 & $9.29 \pm 0.15$ & $8.97-9.53$ \\
\hline Radius & Length $^{\mathrm{b}}$ & 12 & $9.75 \pm 0.22$ & $9.46-10.10$ \\
\hline Ulna & Length $^{\mathrm{b}}$ & 12 & $11.05 \pm 0.28$ & $10.69-11.50$ \\
\hline
\end{tabular}



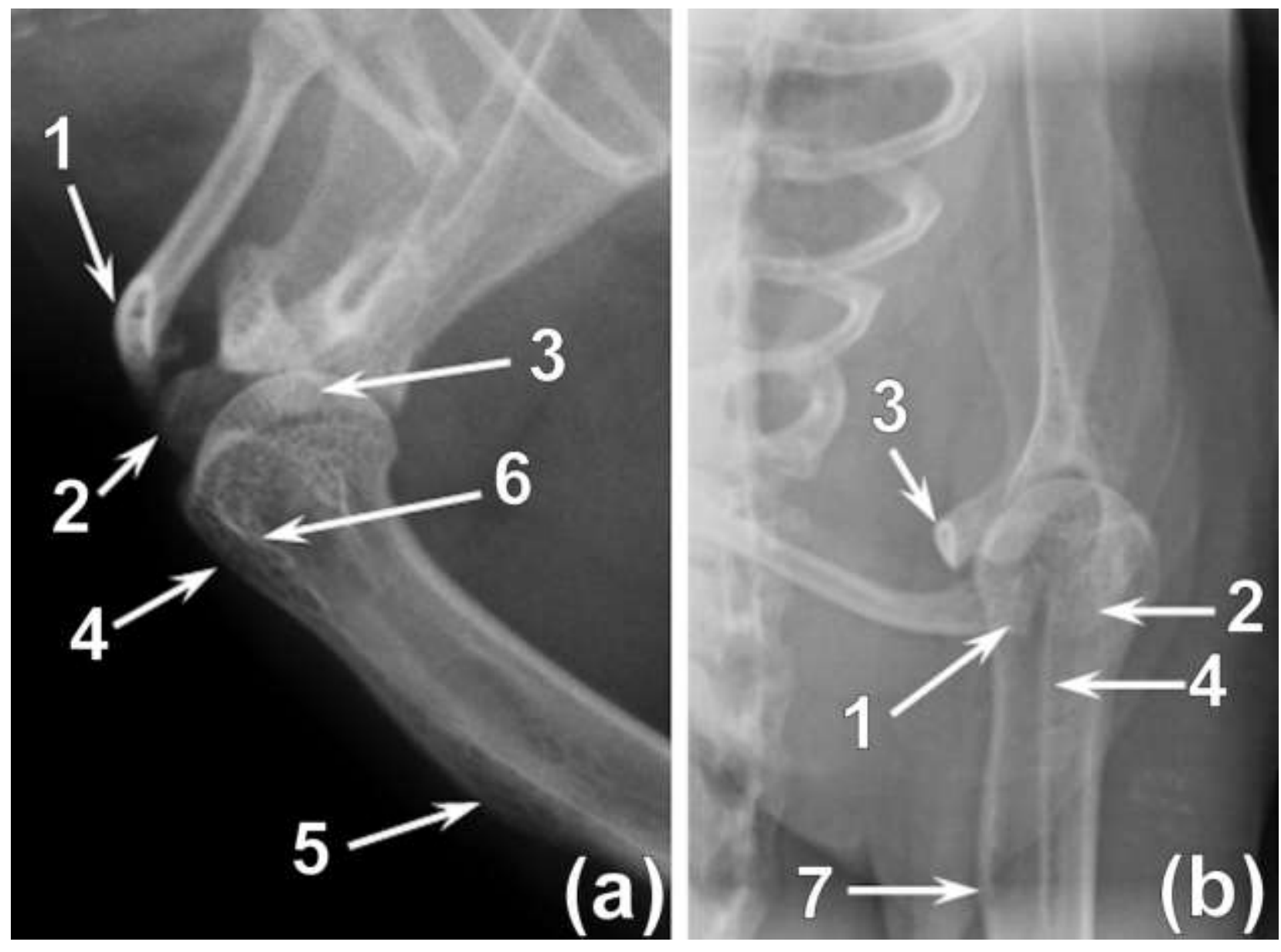

Fig. 2. Mediolateral (a) and $\mathrm{CdCr}(\mathrm{b})$ radiographic views of the right shoulder joint of a 5-year-old female ring-tailed lemur. (1) acromial end of the clavicle, (2) hamate process, (3) distal end of the coracoid process, (4) major tubercular crest, (5) deltoid tuberosity, (6) minor tubercular crest and (7) tuberosity for the $\mathrm{m}$. teres major. 
Table 2. Radiographic measurements $(\mathrm{cm})^{\mathrm{a}}$ of metacarpal bones and phalanges of the right thoracic limb in captive ring-tailed lemurs

\begin{tabular}{|c|c|c|c|}
\hline Bone & Number of animals & $\begin{array}{l}\text { Length } \\
\text { (Mean } \pm \mathrm{SD}) \\
\mathrm{cm}\end{array}$ & Range $(\mathrm{cm})$ \\
\hline MC1 & 12 & $1.23 \pm 0.12$ & $0.90-1.34$ \\
\hline MC2 & 12 & $1.99 \pm 0.27$ & $1.20-2.22$ \\
\hline MC3 & 12 & $2.30 \pm 0.09$ & $2.12-2.40$ \\
\hline MC4 & 12 & $2.22 \pm 0.09$ & $2.08-2.40$ \\
\hline MC5 & 12 & $2.05 \pm 0.11$ & $1.90-2.30$ \\
\hline $\mathrm{P} 1$ of digit 1 & 12 & $1.10 \pm 0.10$ & $0.90-1.21$ \\
\hline $\mathrm{P} 1$ of digit 2 & 12 & $1.50 \pm 0.08$ & $1.39-1.60$ \\
\hline $\mathrm{P} 1$ of digit 3 & 12 & $1.81 \pm 0.08$ & $1.68-1.90$ \\
\hline $\mathrm{P} 1$ of digit 4 & 12 & $1.92 \pm 0.07$ & $1.82-2.00$ \\
\hline $\mathrm{P} 1$ of digit 5 & 12 & $1.54 \pm 0.16$ & $1.04-1.66$ \\
\hline $\mathrm{P} 2$ of digit 2 & 12 & $0.96 \pm 0.04$ & $0.90-1.00$ \\
\hline P2 of digit 3 & 12 & $1.22 \pm 0.05$ & $1.15-1.30$ \\
\hline P2 of digit 4 & 11 & $1.31 \pm 0.07$ & $1.20-1.40$ \\
\hline $\mathrm{P} 2$ of digit 5 & 11 & $1.05 \pm 0.05$ & $0.97-1.10$ \\
\hline $\mathrm{P} 3$ of digit 1 & 12 & $0.62 \pm 0.30$ & $0.40-1.55$ \\
\hline P3 of digit 2 & 10 & $0.38 \pm 0.04$ & $0.30-0.43$ \\
\hline P3 of digit 3 & 10 & $0.42 \pm 0.04$ & $0.36-0.50$ \\
\hline P3 of digit 4 & 10 & $0.43 \pm 0.06$ & $0.30-0.50$ \\
\hline P3 of digit 5 & 10 & $0.39 \pm 0.03$ & $0.30-0.40$ \\
\hline
\end{tabular}

${ }^{\mathrm{a}}$ Radiographic measurements not compensated for magnification.

MC, metacarpal; P1, proximal phalanx; P2, middle phalanx; P3, distal phalanx. 


\section{Scapula}

The scapula is narrow craniocaudally and elongated proximodistally (Fig. 3a). The dorsal margin is longer than the cranial margin (Fig. 3a). The coracoid process is well developed, mediolaterally flattened and directed caudodistally (Fig. 3). On the ML radiographic view of the shoulder joint, the coracoid process projects distally beyond the shoulder joint superimposed on the humeral head (Fig. 2a). On the $\mathrm{CdCr}$ radiographic view of the shoulder joint, it is better visualized and projects distally on the medial side of the shoulder joint (Fig. 2b). The articular surface of the glenoid cavity is peanut-shaped and narrow with a shallow concavity (Fig. 3c). The cranial articular surface of the glenoid cavity is elongated distally (Fig. 3c). The infraglenoid tubercle is represented by a rough surface (Fig. 3c). The supraglenoid tubercle is less prominent (Fig. 3b). The infraspinous fossa is deeply concave, whereas the supraspinous fossa is fairly flat and smaller (Fig. 3a). The area for the origin of the $\mathrm{m}$. teres major is large (Fig. 3a). The spine of the scapula is slanted towards the infraspinous fossa (Fig. 3a). The hamate process is large, long and well developed, extending beyond the glenoid cavity (Figs 2 and 3 ). It is flattened mediolaterally and directed craniodistally. On the ML radiographic view of the shoulder joint, the hamate process projects cranially beyond the shoulder joint (Fig. 2a). On the $\mathrm{CdCr}$ radiographic view of the shoulder joint, it is superimposed on the lateral half of the proximal aspect of the humerus (Fig. 2b). The distal extremity of the hamate

process bears a facet for articulation with the acromial end of the clavicle (Fig. 3b). The suprahamate process is absent (Fig. 3a). 


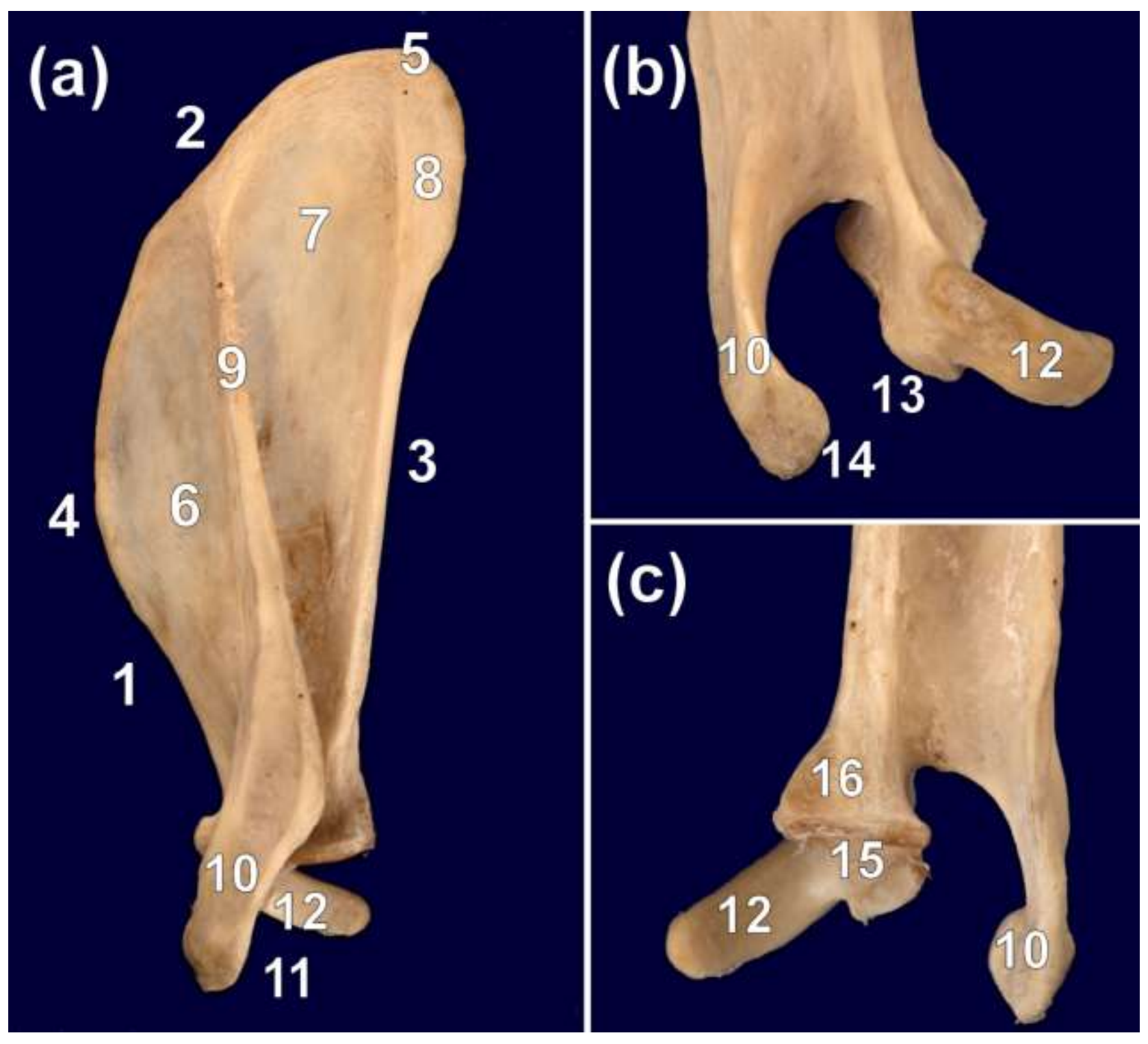

Fig. 3. Lateral (a) and distal aspect of the cranial (b) and caudal (c) views of a bone specimen of the scapula of a 5-year-old female ring-tailed lemur. (1) cranial margin, (2) dorsal margin, (3) caudal margin, (4) cranial angle, (5) caudal angle, (6) supraspinous fossa, (7) infraspinous fossa, (8) area for the origin of m. teres major, (9) scapular spine, (10) hamate process, (11) ventral angle, (12) coracoid process, (13) supraglenoid tubercle, (14) facet for articulation with the acromial end of the clavicle, (15) glenoid cavity and (16) infraglenoid tubercle. 

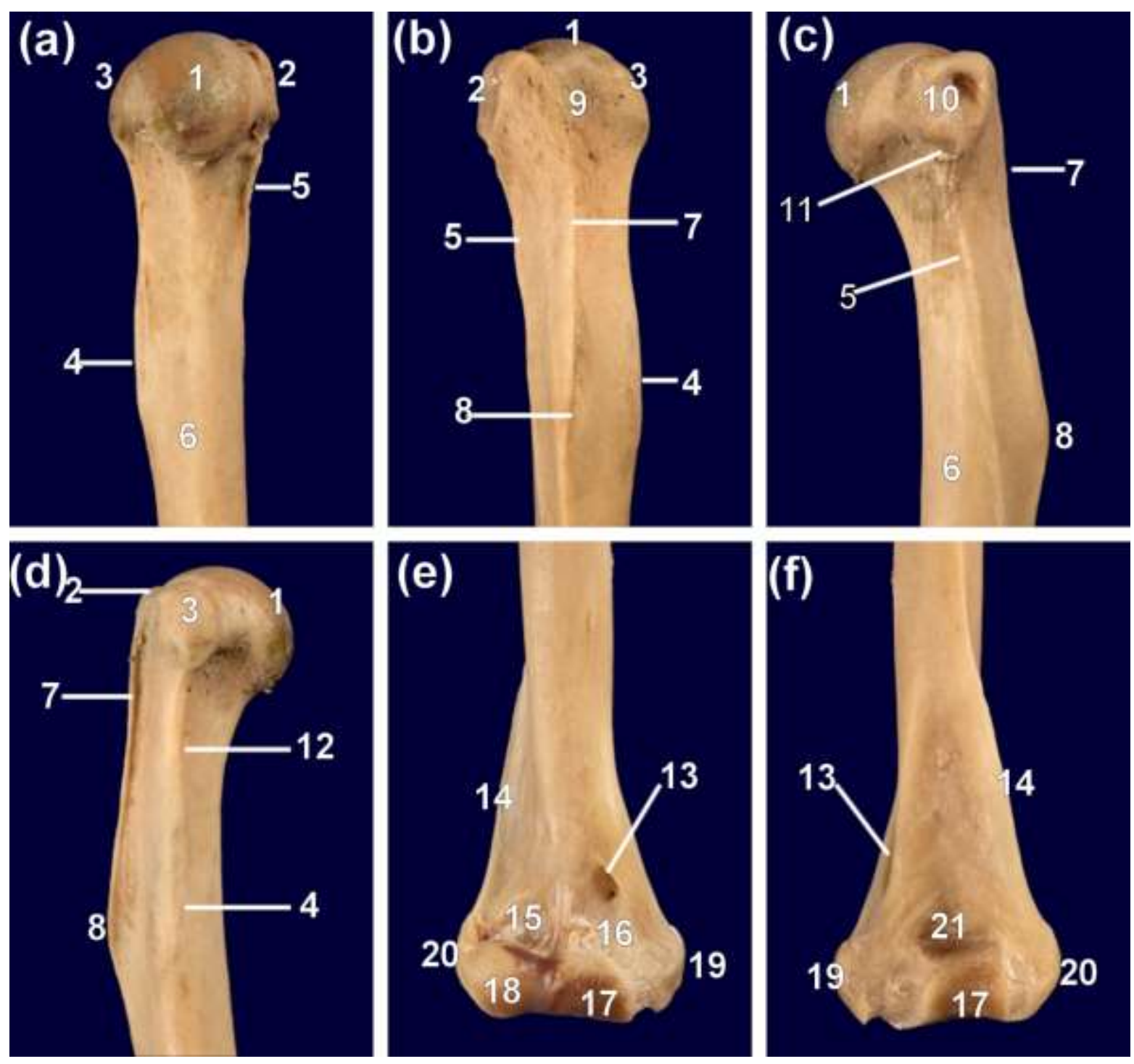

Fig. 4. Caudal (a), cranial (b), lateral (c), medial (d) and cranial (e), caudal (f) views of the proximal and distal, respectively, of a bone specimen of the humerus of a 7-year-old female ring-tailed lemur. (1) humeral head, (2) major tubercle, (3) minor tubercle, (4) tuberosity for the $\mathrm{m}$. teres major, (5) triceps muscle line, (6) body, (7) major tubercular crest, (8) deltoid tuberosity, (9) inter-tubercular groove, (10) Facies $m$. infraspinatus, (11) area for the insertion of the $m$. teres minor, (12) minor tubercular crest, (13) supracondylar foramen, (14) lateral supracondylar crest, (15) radial fossa, (16) coronoid fossa, (17) trochlea humeri, (18) capitulum humeri, (19) medial epicondyle, (20) lateral epicondyle and (21) olecranon fossa. 


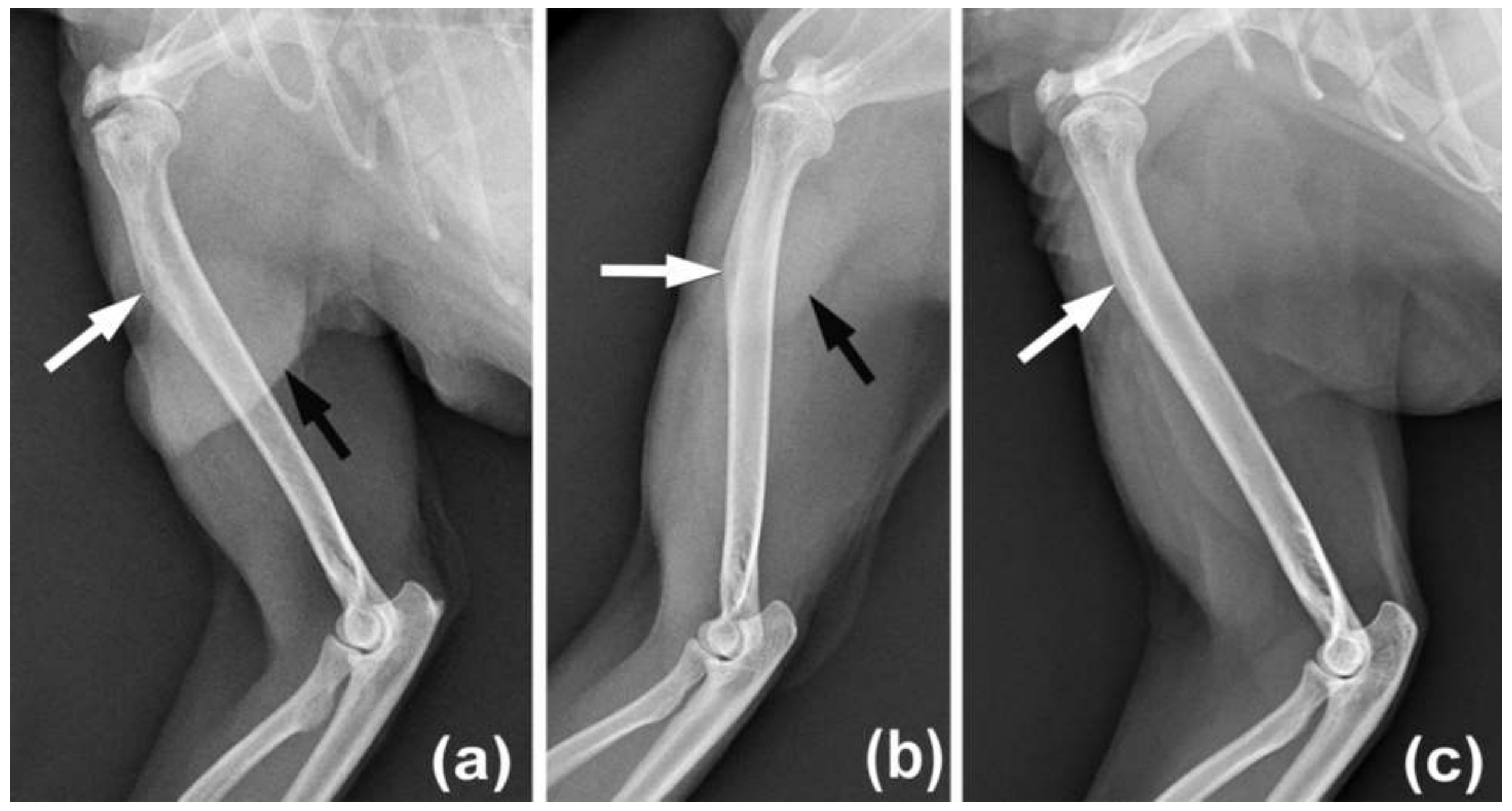

Fig. 5. Mediolateral radiographic view of the humerus of a 22.8-year-old (a), 4.8-year-old (b) and 3.7-year-old (c), male (a, b) and female (c) ring-tailed lemurs. Note the superimposition of the clavicle $(a, c)$ on the scapula, which prevents accurate evaluation of the shoulder joint. Deltoid tuberosity (white arrows) and brachial scent glands (black arrows). 


\section{Humerus}

The humeral head is oval facing caudally (Fig. 4a). The proximal extremity of the major tubercle is flat and does not extend higher than the humeral head (Fig. 4a,b,c). Proximally, the major tubercle has a flat area for the insertion of the $\mathrm{m}$. supraspinatus. Laterally, it presents with an oval depression for the insertion of the $\mathrm{m}$. infraspinatus, which is at the same level as the humeral head (Fig. $4 b, c)$. Just distocaudal to the area of the insertion of the $\mathrm{m}$. infraspinatus, there is a small depression for the insertion of the m. teres minor (Fig. 4c). The minor tubercle is convex and further distal than the humeral head (Fig. 4a,b,d). It presents with a prominent area for the attachment of the $\mathrm{m}$. subscapularis, which faces caudomedially (Fig. 4d). On the $\mathrm{ML}$ and $\mathrm{CdCr}$ radiographic views of the shoulder joint, the major and minor tubercles are further distal than the humeral head (Fig. 2). The humeral neck is well defined caudally (Fig. 4a).

The body of the humerus is slender (Fig. 5). On the ML radiographic view of the humerus, the cranial and caudal cortices of the distal half of the humerus are almost of the same thickness (Fig. 5). An area of soft tissue opacity is superimposed over the proximal half of the humeral diaphysis in male (Fig. 5a,b), but not female animals (Fig. 5c), which is secondary to the brachial scent gland. The crests of the major and minor tubercles are very pronounced located on the cranial and medial surfaces, respectively, of the body of the humerus (Fig. $4 b, d$ ). The crest of the major tubercle is thin and slanted towards the medial side (Fig. 4d). Distally, it is continuous with the deltoid tuberosity. On the ML radiographic view of the shoulder joint, the crest of the minor tubercle is seen as a thin radiopaque longitudinal line superimposed on the proximal half of the humerus (Fig. 2). On the CdCr radiographic view of the shoulder joint, the crest of the major tubercle is seen as a thin longitudinal radiopaque line superimposed on the 


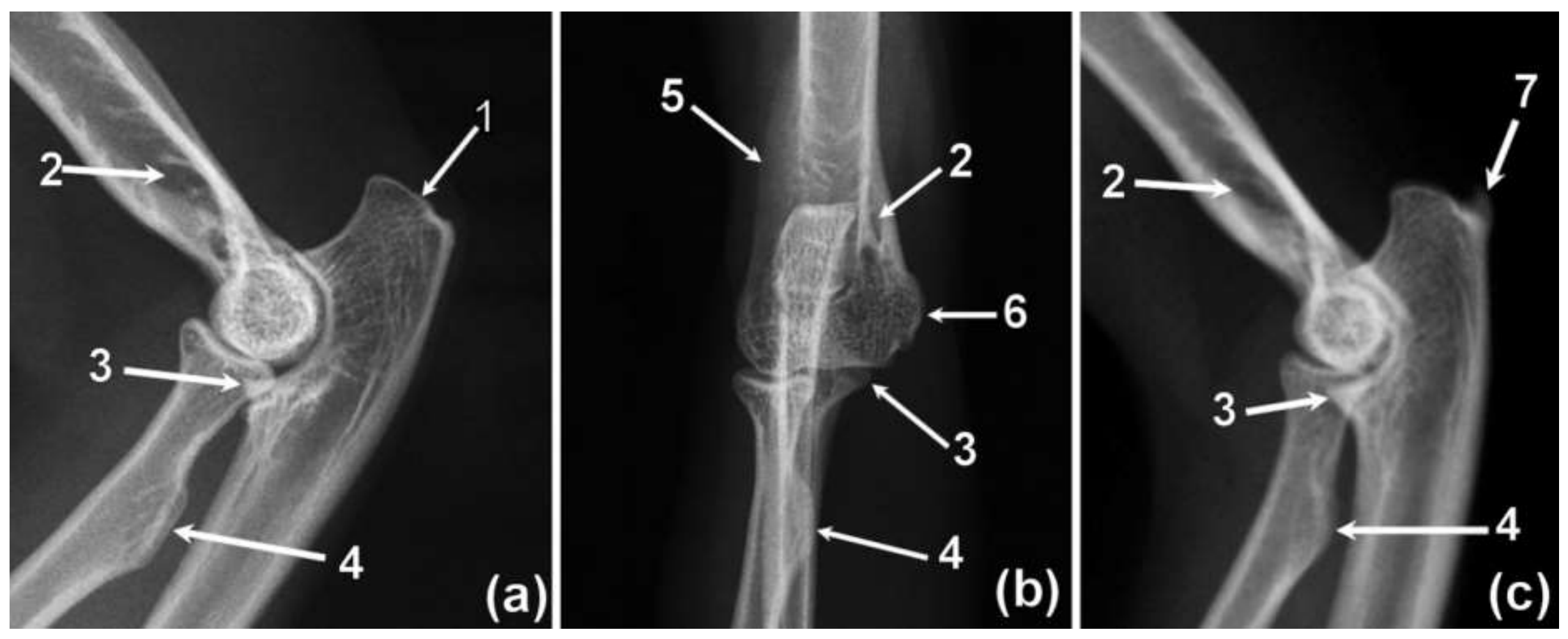

Fig. 6. Mediolateral (a, c) and $\mathrm{CrCd}(\mathrm{b})$ radiographic views of the right elbow joints of a 5-year-old (a, b) and 9.3-year-old (c) female ring-tailed lemur. (1) tuber olecrani, (2) supracondylar foramen, (3) medial coronoid process, (4) radial tuberosity, (5) lateral supracondylar crest, (6) medial epicondyle and (7) olecranon spur. 
body of the humerus (Fig. 2b). The deltoid (Fig. 4b,c,d) and teres major (Fig. 4a,b,d) tuberosities are very pronounced. The deltoid tuberosity projects cranially on the ML radiographic view of the humerus (Fig. 5). The proximal third of the lateral surface of the body of the humerus is marked by the triceps muscle line (Fig. 4c), which extends from the caudodistal aspect of the major tubercle to the distal aspect of the cranially located deltoid tuberosity. Cranial to the triceps muscle line and caudal to the crest of the major tubercle, the proximal third of the lateral surface of the body bears a shallow longitudinal groove (Fig. 4c).

The lateral supracondylar crest is well developed (Figs. 4e,f and 6a). The medial epicondyle is larger and better developed than its lateral counterpart (Fig. 4e,f). The medially located supracondylar foramen slopes from medial to craniodistal (Fig. 4e,f). On the CrCd radiographic view of the elbow joint, the supracondylar foramen is seen as two ovoid radiolucent areas just proximal to the medial epicondyle (Fig. 6b). The articular surface of the humeral condyle is fairly symmetrical (flat) and presents with a distinct medially located trochlea humeri and a laterally located capitulum humeri (Fig. $4 e, f)$. The capitulum humeri are grooved, whereas the trochlea humeri, are not grooved (Fig. 4e). The radial and coronoid fossae are well defined (Fig. 4e). The radial fossa is more prominent than the coronoid fossa. The horizontally aligned olecranon fossa is shallow and fairly triangular with rounded angles (Fig. 4f). On the $\mathrm{CrCd}$ radiographic view of the elbow joint, the olecranon fossa has an ovoid shape and is elongated in a mediolateral direction (Fig. 6b). The supratrochlear foramen is absent. 

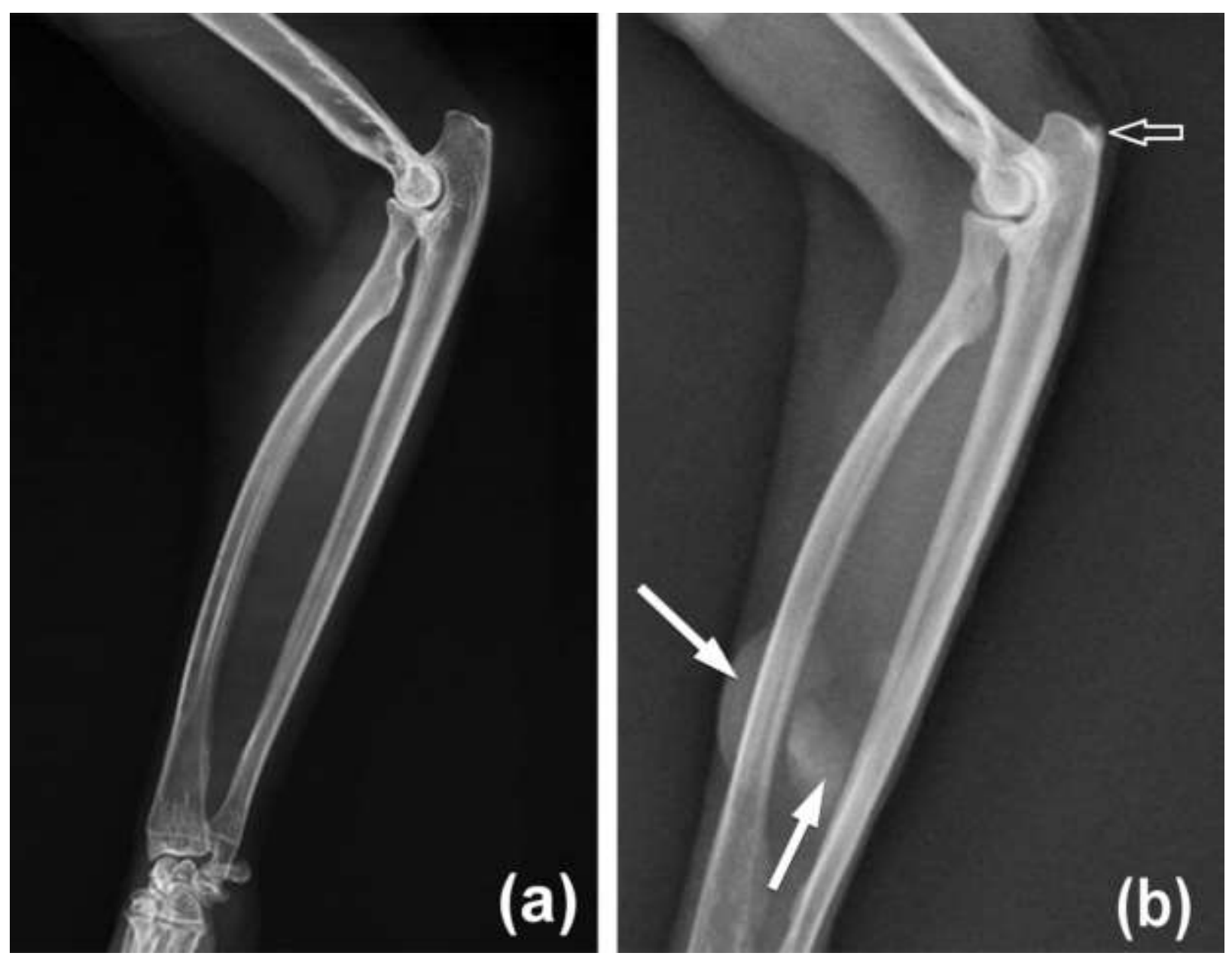

Fig. 7. Mediolateral radiographic view of the right antebrachium of a 5-year-old female (a) and 22.8-yearold male (b) ring-tailed lemurs. (a, b) Note the wide interosseous space. (b) Note also the olecranon spur (open white arrow) and areas of increased soft tissue opacity (white arrows) in the distal half of the antebrachium due to presence of the antebrachial scent gland in the male animal.

\section{Radius and ulna}

Radius and ulna are separate bones of similar width with a wide inter-osseous space. The ulna is longer than the radius (Fig. 7). The radial head is distinct and fairly elliptical in shape sloping from lateral to medial (Fig. 8a). It has a concave articular fovea proximally and is well demarcated from the body by a long distinct neck (Figs 6 and $8 a, c)$. The body of the radius curves cranially along the longitudinal axis of the bone 

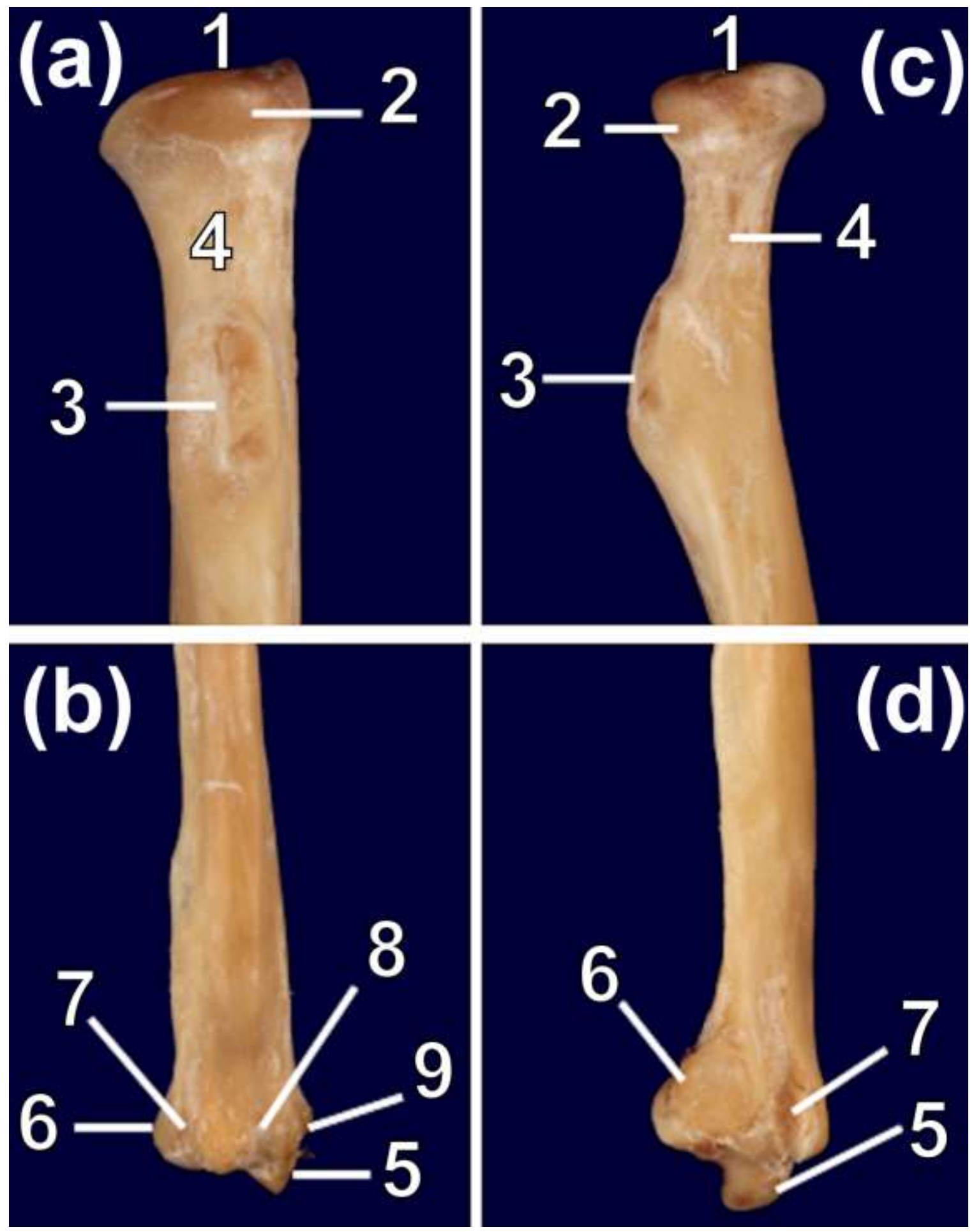

Fig. 8. Caudal (a), cranial (b) and lateral (c, d) views of the proximal (a, c) and distal (b, d) aspects of a bone specimen of the radius of a 7-year-old female ring-tailed lemur. (1) radial head fovea, (2) articular circumference, (3) radial tuberosity, (4) radial neck, (5) styloid process, (6) ulnar notch, (7) lateral tendon groove, (8) middle tendon groove and (9) medial tendon groove. 
when viewed from lateral or medial (Fig. 7). The distal third of the bone is rotated towards the lateral side. Distal to the neck, the caudal surface of the body bears a prominent radial tuberosity, which is relatively distal located (Figs 6 and $8 a, c)$. The radial tuberosity is marked by a short groove (Fig. 8a). The body of the radius bears a deep longitudinal groove distal to the radial tuberosity. Further, it presents with longitudinal grooves craniolaterally and craniomedially. The caudal surface of the distal aspect of the body of the radius bears a broad flat surface. The radial trochlea is broader than the head and is flared on the ML and DPa radiographic views of the carpus (Fig. 9). The radial trochlea has three cranial grooves for the passage of tendons (Fig. 8b). The middle and lateral grooves are separated by a wide tubercle. The medially located styloid process is pointed (Fig. 8b,d). The ulnar notch is fairly flat (Fig. 8d).

The ulna bears a proximally directed square-shaped tuber olecrani (Figs 6 and 10a,c). A small osseous spur is seen radiographically on the caudoproximal aspect of the tuber olecrani in two animals (Figs $6 \mathrm{c}$ and $7 \mathrm{~b}$ ). The anconeal process is short and wide (Fig. 10a). The prominent and rounded medial coronoid process (Fig. 10a) appears pointed on the ML radiographic view of the elbow joint (Fig. 6a,c). The craniolaterally located radial notch is a fairly rounded projection with a single articular facet sloping from medially to laterally (Fig. 10a,c). The radial notch projects cranially from the surface of the ulna (Fig. 10a,c). The body of the ulna is slightly curved with the lateral and medial surfaces marked by prominent longitudinal grooves. Just distal to the medial coronoid process, the body of the ulna bears a groove for the insertion of the $\mathrm{m}$. brachialis (Fig. 10a). The ulnar head is well developed (Figs 9 and 10). The styloid process is bulbous with a convex articular surface for articulation with the ulnar and accessory carpal bones (Figs 9 and 10). The articular circumference slopes in a 


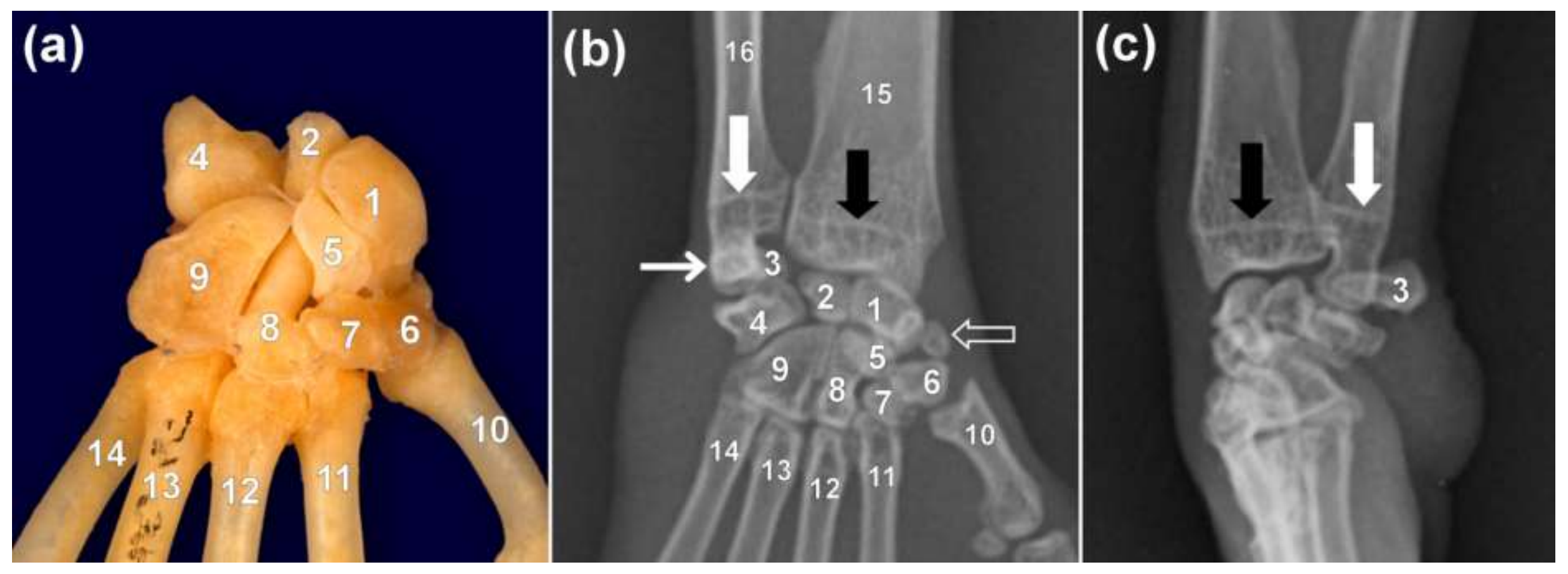

Fig. 9. Dorsal (a), DPa (b) and ML (c) views of a bone specimen (a) and radiographs (b, c) of an adult male (a) and 5-year-old female (b, c) ring-tailed lemurs. Note the medial divergence of the first MC bone from the rest of the MC bones (a, b). Note also the radial (thick black arrow) and ulnar (thick white arrow) transverse physeal scars (b, c). The increased mineral opacity (thin white arrow) is a result of superimposition of the styloid process of the ulna and accessory carpal bone. Note the presence of a sesamoid bone of the $\mathrm{m}$. abductor pollicis longus on the medial aspect of the carpus (open white arrow). (1) radial carpal bone, (2) intermediate carpal bone, (3) accessory carpal bone, (4) ulnar carpal bone, (5) central carpal bone, (6) first carpal bone, (7) second carpal bone, (8) third carpal bone, (9) fourth carpal bone, (10) first MC bone, (11) second MC bone, (12) third MC bone, (13) fourth MC bone, (14) fifth MC bone, (15) radius and (16) ulna. 


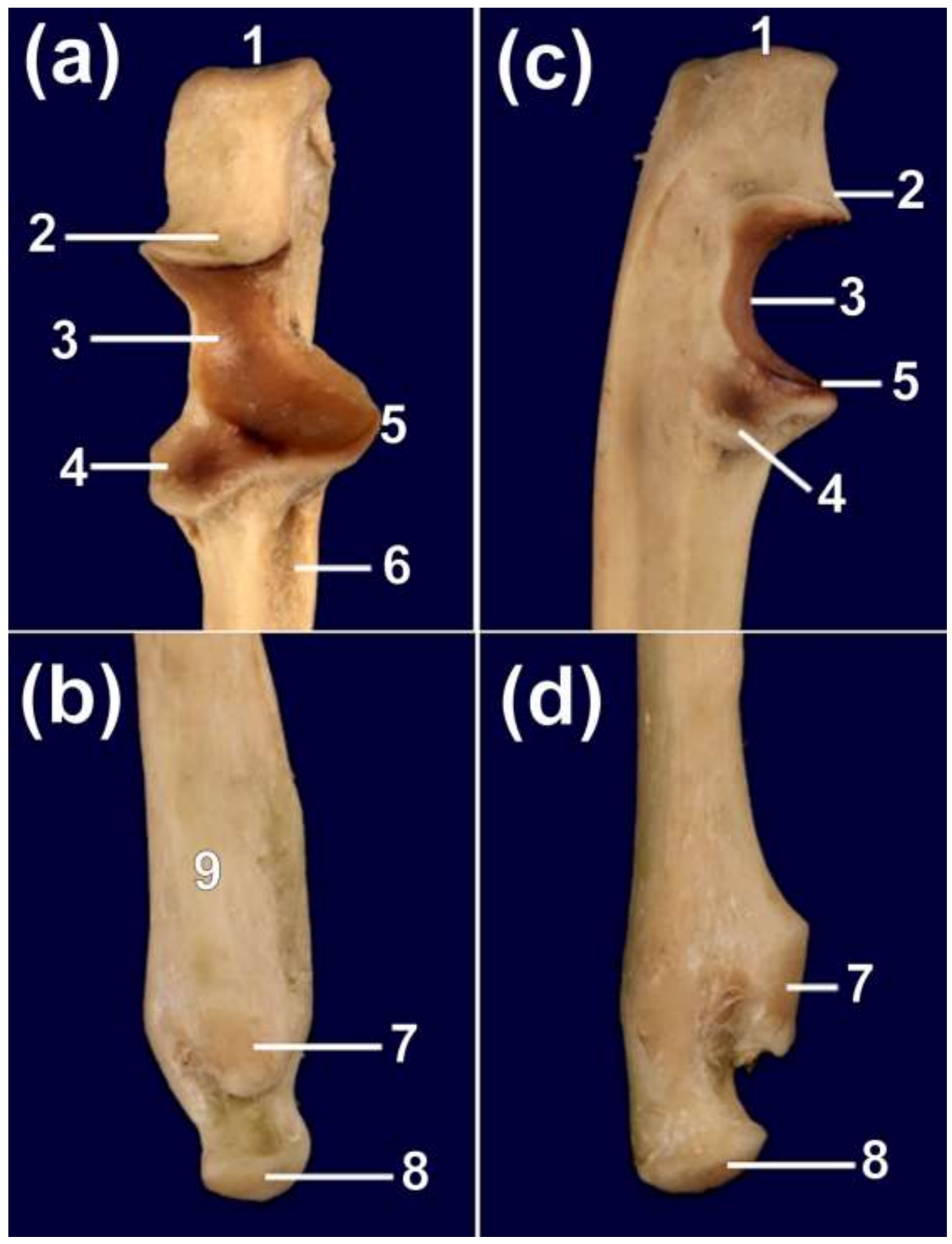

Fig. 10. Cranial $(a, b)$ and lateral (c, d) views of the proximal $(a, c)$ and distal $(b, d)$ aspect of a bone specimen of the ulna of a 5-year-old female ring-tailed lemur. (1) tuber olecrani, (2) anconeal process, (3) trochlear notch, (4) radial notch, (5) medial coronoid process, (6) groove for the insertion of $\mathrm{m}$. brachialis, (7) articular circumference, (8) styloid process and (9) area for the origin of the m. pronator quadratus. 
craniocaudal direction and is increased from the surface of the body of the ulna (Fig. 10d). It forms an approximately ninety degree angle with the styloid process (Fig. 10d). Just proximal to the articular circumference, the cranial surface of the body of the ulna presents with a flat surface for the origin for the $\mathrm{m}$. pronator quadratus and is bordered medially by a crest (Fig. 10b). The radial and ulnar physeal scars are linear-shaped (Fig. 9). On the ML radiographic view of the antebrachium, areas of soft tissue opacity are noted summating with the distal half of the antebrachium in male animals as a result of the antebrachial scent glands (Fig. 7b).

\section{Carpus}

The carpal bones form a convex dorsal outline. There are nine carpal bones arranged in three rows. The proximal row comprises the radial, intermediate, ulnar and accessory carpal bone. The central carpal bone is the only bone situated in the middle row. The distal row comprises the first, second, third and fourth carpal bones (Fig. 9). The radial carpal bone is the most medial carpal bone in the proximal row (Fig. 9a,b) and reveals a palmaromedial prominent tuberosity. The tuberosity on the palmaromedial aspect of the radial carpal bone is seen as an ovoid area of increased bone opacity on the medial aspect of the radial carpal bone on the DPa radiographic view of the carpus (Fig. 9b). The ulnar carpal bone (Fig. 9b) presents with a small palmarly directed process. Proximally, the bone bears two articular facets for the accessory carpal bone and styloid process of the ulna. The intermediate carpal bone is the smallest bone in the proximal row situated between the radial and ulnar carpal bones (Fig. 9). The palmarolaterally directed accessory carpal bone is $\mathrm{Y}$-shaped when viewed from proximal. The dorsal surface of the bone has two articular facets, one for the styloid process of the ulna and 
the other for the ulnar carpal bone. The central carpal bone is crescent-shaped and situated in the middle row (Fig. 9). The fourth carpal bone is the largest carpal bone located on the lateral side of the distal row (Fig. 9). It is wedge-shaped when viewed from dorsally, and articulates both with the fourth and fifth metacarpal bones. The first to third carpal bones in the distal carpal row articulate with their corresponding metacarpal bones (Fig. 9). A sesamoid bone for the m. abductor pollicis longus was always seen on the medial aspect of the carpus (Fig. 9b).

\section{Metacarpus and digits}

There are five metacarpal bones (Fig. 11), namely (mediolateral sequence) metacarpal (MC) bones $1-5$. The MC bones are widely spread and equally developed in terms of width. They are relatively shorter in relation to the length of their corresponding digits. The first $M C$ bone diverges further medial from the rest of the $M C$ bones, with the dorsal and palmar surfaces facing almost medially and laterally, respectively, (Fig. 11). There are five digits. Digits $2-5$ each have three phalanges: the proximal (P1), middle (P2) and distal (P3) phalanges. Digit 1 has only phalanges P1 and P3 (Fig. 11). The P1 phalanx is the longest, whereas the $P 3$ phalanx is the shortest (Fig. 11). Each metacarpophalangeal joint has paired proximal sesamoid bones on the palmar aspect. The abaxial proximal sesamoid bones of digits 2 and 3 are longer than their counterparts, whereas the axial proximal sesamoid bones of digits 4 and 5 are longer than their counterparts. An ovoid ossicle was always seen on the palmar aspect at the inter-phalangeal joint of digit 1 (Fig. 11). The soft tissue opacity surrounding the MC bones, including the carpus and metacarpophalangeal joints, is prominent (Fig. 11). 


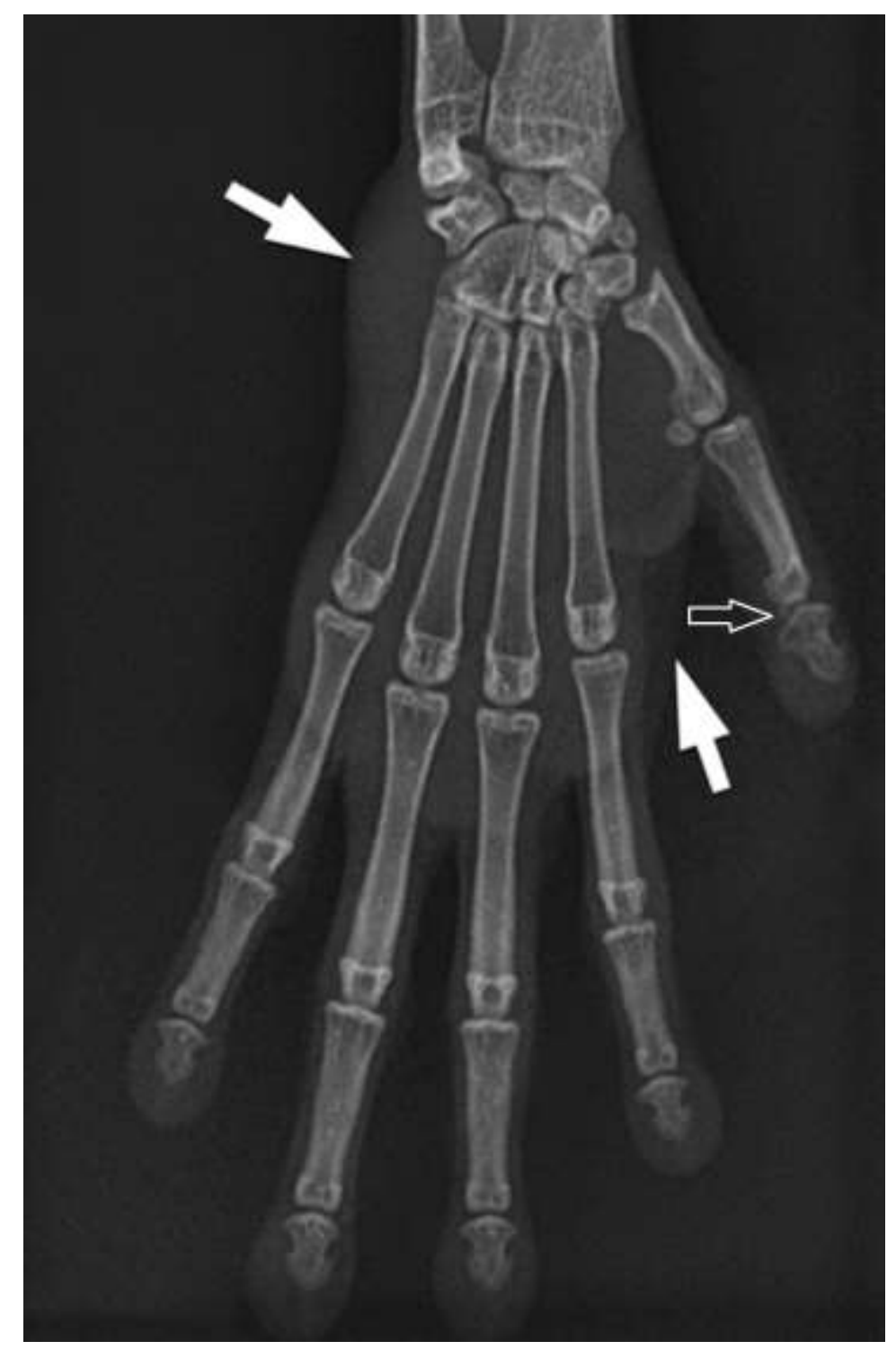

Fig. 11. Dorsopalmar radiographic view of the right manus of a 5-year-old female ring-tailed lemur. Note the widely spread MC bones and digits. Note also the medial divergence of the first MC bone, thick soft tissues around the carpus, MC bones and metacarpophalangeal joints (white arrows) and an ovoidshaped ossicle (open white arrow) at the inter-phalangeal joint of the first digit.

\section{Discussion}

Strepsirrhines are predominantly arboreal animals with the exception of the ring-tailed lemur, which spends up to one-third of its time on the ground (Ankel-Simons, 2007). The 
ring-tailed lemur is a quadruped with its locomotor activity involving climbing, jumping and running (Ankel-Simons, 2007).

Strong flexor muscles and flexibility of the thoracic limb joints are important in arboreal quadrupeds. The long and well-developed clavicle and small and shallow glenoid cavity observed in this study indicate that the shoulder joint in this species is freely and highly mobile (Ankel-Simons, 2007) and capable of a large range of movements. The clavicle, which attaches to the manubrium sterni and acromion of the scapula in this species, keeps the scapula in a lateral position, which provides the shoulder joint with high mobility (Ankel-Simons, 2007). The distal elongation of the cranial articular surface of the glenoid cavity is believed to prevent luxation of the humeral head in extreme retraction of the humerus.

The narrow scapula with a long dorsal margin and a short cranial margin allows rapid movement of the thoracic limb and at the same time provides an adequate area for insertion of the scapulovertebral muscles, which support the body weight and absorb the shock of the footfall at the end of a quadrupedal leap. This is probably an adaptation to both arboreal and terrestrial lifestyles.

The abduction ability of the shoulder joint is supported by the presence of a broad and long acromion process and the location of the insertion of the $\mathrm{m}$. infraspinatus at the same level as the head of the humerus. The broad and long acromion process increases the power of the $\mathrm{m}$. deltoideus in the abduction of the humerus (Taylor, 1974). In some African mammals, it was found that the insertion of the $\mathrm{m}$. infraspinatus above the level of the humeral head diminishes its abduction function (Hopwood, 1947).

The fairly symmetrical (flat) distal articular surface of the humerus observed in this species provides a suitable surface for a rocking movement of the ulna aiding in 
supination (Taylor, 1974). Further, the well-developed lateral supracondylar crest is the origin of the $\mathrm{m}$. brachioradialis, a supinator of the antebrachium. The craniolaterally located radial notch with a single articular facet that projects cranially from the surface of the ulna allows greater rotation of the radius (Taylor, 1974; Gonyea, 1978). The elliptically shaped radial head acts as a cam that transmits the radius' eccentric motion and hence permits rotation of the radius without stretching of the inter-osseous ligament (Gonyea, 1978). Additionally, the elevation of the ulnar articular circumference from the body, well-developed body and ulnar head acts as a pivot, which supports the radius during rotation movement.

The presence of strong flexor muscles of the thoracic limb is supported by the presence of the following features: a large area and prominent tuberosity, which provides the origin and insertion, respectively, of the $\mathrm{m}$. teres major, which flexes the humerus, a prominent medial epicondyle, which provides the origin of the flexor muscles of the manus and a relatively distally located and prominent radial tuberosity, which provides the insertion for the $\mathrm{m}$. biceps brachii which flexes the elbow joint. Additionally, the presence of a well defined radial fossa indicates that the thoracic limb in this species is adapted for elbow flexion (Fleagle and Simons, 1995).

The oval caudally facing humeral head, lack of extension of the greater tubercle proximal to the humeral head and the proximally directed tuber olecrani are characteristic features of arboreal quadrupedal primates (Fleagle and Simons, 1995; Ankel-Simons, 2007). A slightly curved body of the ulna has been observed in other small arboreal quadrupedal primates (Fleagle and Simons, 1995). Large arboreal quadrupedal primates have a greater curvature of the body of the ulna as a result of regular use of the thoracic limb in a more flexed position (Fleagle and Simons, 1995). 
The presence of the central carpal bone in skeletally mature ring-tailed lemurs is different from humans, domestic cats and dogs (Nickel et al., 1986). The central carpal bone has also been reported in other strepsirrhines (Osman Hill, 1953; Jouffroy, 1975). The medial divergence of the first $\mathrm{MC}$ bone from the rest of the $\mathrm{MC}$ bones observed in ring-tailed lemurs is associated with the manus being an efficient grasping tool during feeding and locomotion (Ankel-Simons, 2007). The widely spread and short MC bones provide a large space and allow greater effectiveness of the muscles responsible for small movements of the digits (Taylor, 1974). The palmarolaterally directed accessory carpal bone is associated with ulnar deviation (Taylor, 1974).

The presence of two proximal sesamoid bones palmar to the metacarpophalangeal joint of all digits observed in ring-tailed lemurs is similar to wild felids (Kirberger et al., 2000; 2005) but different from humans (Msamati and Igbigbi, 2001; Dharap et al., 2007). In humans, two proximal sesamoid bones are always present palmar to the metacarpophalangeal joint of the thumb and less frequently to rarely in other fingers (Msamati and Igbigbi, 2001; Dharap et al., 2007). Variation in the length between abaxial and axial proximal sesamoid bones of the same digit has also been observed in wild feline species (Kirberger et al., 2000; 2005). The ovoid ossicle seen at the inter-phalangeal joint of digit 1 in all animals suggests that the ossicle is a normal anatomical finding in this species. It is most likely that the ossicle is intra-articular as described for the great toe in humans (Suwannahoy et al., 2012) and should be differentiated from an avulsion fracture or intra-articular mineralized body.

Areas of increased soft tissue opacity seen superimposed over the proximal half of the humerus and the distal half of the antebrachium in male animals are a result of scent gland and should not be mistaken with soft tissue masses such as neoplasia, 
hematomas, seromas, granulomas, cellulitis, abscesses and cysts. In this study, scent glands (brachial and antebrachial) were seen only in male animals on radiographic examination. Wilson and Hanlon (2010) reported that the brachial scent gland is barely developed in female ring-tailed lemurs, whereas the antebrachial scent gland is present in both sexes.

The thick soft tissue opacity seen around the carpus, MC bones and metacarpophalangeal joints on the DPa radiographic view of the manus is different from domestic cats and dogs (Thrall and Robertson, 2011) and should not be mistaken as soft tissue swelling as a result of cellulitis, neoplasia, abscesses or inflammation due to trauma or a foreign body.

The radiographic measurements of bones obtained in this study might be slightly increased due to the effect of magnification (Thrall, 2013). However, we hope the length measurements might provide useful information for future studies.

In summary, the thoracic limb morphology of the ring-tailed lemur supports the presence of strong flexor muscles and flexibility of the thoracic limb joints, which is important in arboreal quadrupedal locomotion. However, the proximal part of the thoracic limb is modified for both arboreal and terrestrial quadrupedal locomotion. The osteology and radiographic anatomy of the thoracic limb of the ring-tailed lemur is important for accurate interpretation and diagnosis of musculoskeletal diseases involving the thoracic limb. Further, studies are needed to determine the importance of the inter-phalangeal ossicle in the first digit for the biomechanics of the first digit. 


\section{Acknowledgements}

The authors would like to thank the Organisation for Women in Science for the Developing World (OWSD), Swedish International Development Cooperation Agency (SIDA), University of Pretoria, Johannesburg (JHB) and Bristol zoos for supporting this study. The Transvaal museum and Dr. Shaw Badenhorst for supplying bone specimens. Dr. Brett Gardner, Dr. Kathryn Perrin, Ms. Fania Mohlala, sisters and animal handlers of Onderstepoort Academic Hospital, Bristol and JHB zoos for their assistance during radiographic examination. Mrs. Wilma Olivier and Mrs. Charmaine Vermeulen of University of Pretoria for their assistance in administrative work and photography, respectively.

\section{References}

Ankel-Simons, F., 2007: Primate Anatomy: An Introduction. Boston: Academic Press.

Backues, K. A., J. P. Hoover, R. J. Bahr, A. W. Confer, J. A. Chalman, and M. L. Larry, 2001: Multifocal pyogranulomatous osteomyelitis resembling chronic recurrent multifocal osteomyelitis in a lemur. J. Am. Vet. Med. Assoc. 218, 250-253.

Budnitz, N., and K. Dainis, 1975: Lemur catta: Ecology and Behaviour. In: Lemur Biology (I. Tattersall and R. W. Sussman, eds). New York: Plenum Press, pp. 219-235.

Burk, R. L., and D. A. Feeney, 2003: Small animal radiology and ultrasonograhy. A Diagnostic Atlas and Text. Philadelphia: Saunders. 
Dharap, A. S., H. Al-Hashimi, S. Kassab, and M. F. Abu-Hijleh, 2007: Incidence and ossification of sesamoid bones in the hands and feet: A radiographic study in an Arab population. Clin. Anat. 20, 416-423.

Fleagle, J. G., and E. L. Simons, 1995: Limb skeleton and locomotor adaptations of Apidium phiomense, an Oligocene Anthropoid from Egypt. Am. J. Phys. Anthropol. 97, 235-289.

Gonyea, W. J., 1978: Functional implications of felid forelimb anatomy. Acta. Anat. 102, $111-121$

Hopwood, A. T., 1947: Contributions to the study of some African Mammals-III. Adaptations of the bones of the forelimb of the lion, leopard and cheetah. J. Linn. Soc. Zool. 41, 259-271.

IUCN, 2014: IUCN Red List of Threatened Species. Version 2014.2. Available at: http://www.iucnredlist.org, accessed on 24 July 2014.

Jouffroy, F. K., 1975: Osteology and Myology of the Lemuriform Postcranial Skeleton. In: Lemur Biology (I. Tattersall and R. W. Sussman, eds). New York: Plenum Press. pp. 149-192.

Jungle, R. E., 2003: Prosimians. In: Zoo and Wild Animal Medicine (M. E. Fowler and R. E. Miller, eds). Missouri: Saunders. pp. 334-346.

Jungle, R. E., K. G. Mehren, T. P. Meehan, G. J. Crawshaw, M. C. Duncan, L. Gilula, F. Gannon, G. Finkel, and M. P. Whyte, 1994: Periarticular hyperostosis and renal disease in six black lemurs of two family groups. J. Am. Vet. Med. Assoc. 205, 1024-1029. 
Kirberger, R. M., H. B. Groenewald, and W. M. Wagner, 2000: A radiological study of the sesamoid bones and Os meniscus of the cheetah (Actinonyx jubatus). Vet. Comp. Orthopaed. 13, 172-177.

Kirberger, R. M., W. M. du Plessis, and P. H. Turner, 2005: Radiologic Anatomy of the normal appendicular skeleton of the lion (Panthera leo). Part 2: Pelvic limb. J. Zoo. Wildl. Med. 36, 29-35.

Msamati, B. C., and P. S. Igbigbi, 2001: Radiographic appearance of sesamoid bones in the hands and feet of Malawian subjects. Clin. Anat. 14, 248-253.

Nickel, R., A. Schummer, E. Seiferle, J. Frewein, H. Wilkens, and K. H. Wille, 1986: The Anatomy of the Domestic Animals. Berlin: Springer-Verlag.

Nowak, R. M., 1999: Order Primate. In: Walker's Mammals of the World (R. M. Nowak, ed.). Baltimore: The Johns Hopkins University Press. pp. 490-631.

Osman Hill, W. C., 1953: Primates (Comparative Anatomy and Taxonomy). I. Strepsirhini. Edinburgh: University Press. pp. 50-380.

Owens, J. M., and D. N. Biery, 1999a: The scope of diagnostic imaging. In: Radiographic Interpretation for the Small Animal Clinician (J. M. Owens and D. N. Biery, eds). Baltimore: Williams and Wilkins. pp. 1-8.

Owens, J. M., and D. N. Biery, 1999b: Principles of radiographic interpretation. In: Radiographic Interpretation for the Small Animal Clinician (J. M. Owens and D. N. Biery, eds). Baltimore: Williams and Wilkins. pp. 9-13.

Roberts, D., and I. Davidson, 1975: The lemur scapula. In: Lemur Biology (I. Tattersall and R. W. Sussman, eds). New York: Plenum Press. pp. 125-147. 
Smallwood, J. E., and K. A. Spaulding, 2013: Radiographic anatomy of the appendicular skeleton. In: Textbook of Veterinary Diagnostic Radiology (D. E. Thrall, ed.). Missouri: Saunders Elsevier. pp. 224-251.

Suwannahoy, P., T. Srisuwan, N. Pattamapaspong, and P. Mahakkanukrauh, 2012: Intra-articular ossicle in interphalangeal joint of the great toe and clinical implication. Surg. Radiol. Anat. 34, 39-42.

Taylor, M. E., 1974: The functional anatomy of the forelimb of some African Viverridae (Carnivora). J. Morph. 143, 307-335.

Thrall, D. E., 2013: Introduction to radiographic interpretation. In: Textbook of Veterinary Diagnostic Radiology (D. E. Thrall, ed.). Missouri: Saunders Elsevier. pp. 74-86.

Thrall, D. E., and I. D. Robertson, 2011: The thoracic limb. In: Atlas of Normal Radiographic Anatomy and Anatomic Variants in the Dog and Cat. Missouri: Elsevier Saunders. pp. 69-98.

Tomson, F. N., and R. R. Lotshaw, 1978: Hyperphosphatemia and hypocalcemia in lemurs. J. Am. Vet. Med. Assoc. 173, 1103-1106.

Warwick, R., 1951: A sarcoma of bone in a ring-tailed lemur. J. Pathol. Bacteriol. 63, 499-501.

Weber, M., N. Lamberski, and K. Heriot, 1995: An idiopathic proliferative disease of bone in two species of ruffed lemur (Varecia variegata variegata and Varecia variegata rubra). In: Proceedings of the joint conference of the American Association of Zoo Veterinarians, Wildlife Disease Association, American Association of Wildlife Veterinarians. Lansing, Michigan. pp. 268.

Wilson, D. N., and E. Hanlon, 2010: Lemur catta (Primates: Lemuridae). Mamm. Species 42, 58-74. 